\title{
The Analysis of Water Spray Feed-forward Compensation Based on Desuperheating Model
}

\author{
Sijia Tian \\ School of North China Electric Power University, Baoding 071000, China; \\ 1360727243@qq.com
}

Keywords: feedforward, compensation model, mismatch spray, desuperheating model

\begin{abstract}
. as for larger hysteresis control object, when causing a large fluctuations in output, feedback can't timely effect influence the output of the system, directly impacting on control quality, a better solution to this kind of problem is to introduce the feedforward control system. In this paper, the analysis of the water spray desuperheating model to the big lag control object feedforward compensation scheme and the model mismatch problem are given.
\end{abstract}

\section{The feedforward control principle and characteristics}

In simple terms, it is according to the change of the disturbance variable to compensate for its effect on the controlled variable, so as to achieve the controlled variables completely being .not affected by disturbance variable control mode. This kind of control mode of open loop control according to interference called feedforward control, hereinafter being referred to as FFC

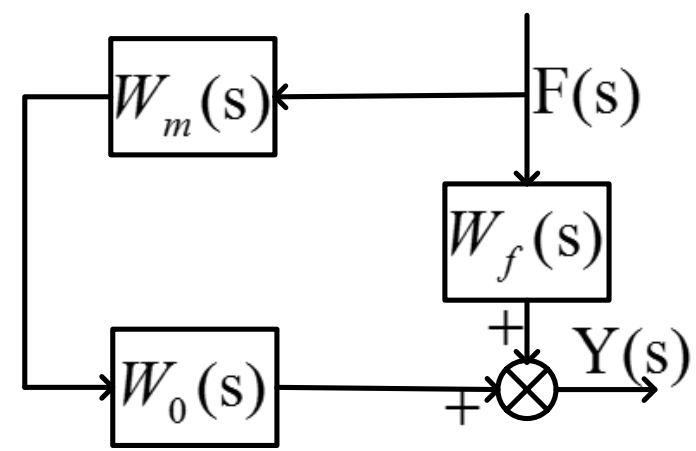

figure1 Feedforward control system block diagram

In the Diagram, $W_{m}(\mathrm{~s})$ is the feedforward controller, the transfer function ${ }_{f}(\mathrm{~s})$ is for process disturbance channel transfer function; $W_{0}(\mathrm{~s})$ is For process control channel transfer function; ${ }^{\mathrm{F}(\mathrm{s})}$ is the measurable uncontrolled disturbances; ${ }^{Y(s)}$ is was accused of parameters

$$
Y(\mathrm{~s})=W_{f}(\mathrm{~s}) \mathrm{F}(\mathrm{s})+W_{m}(\mathrm{~s}) W_{0}(\mathrm{~s}) \mathrm{F}(\mathrm{s})
$$

thus

$$
\frac{Y(\mathrm{~s})}{\mathrm{F}(\mathrm{s})}=W_{f}(\mathrm{~s})+W_{m}(\mathrm{~s}) W_{0}(\mathrm{~s})
$$

if

$$
\frac{Y(\mathrm{~s})}{\mathrm{F}(\mathrm{s})}=0
$$

We can get Feed-forward controller model 


$$
W_{m}(\mathrm{~s})=-\frac{W_{f}(\mathrm{~s})}{W_{0}(\mathrm{~s})}
$$

By the controller model, feedforward control is carried out in accordance with the disturbance effect of the size of the control, so the control is timely. If the compensation function can not produce deviation, it means the controlled system has very strong ability to resist outside interference.

\section{The structure of feedforward control system}

In the practical process control, feedforward control has many kinds of structure forms

\section{1 static feedforward control system}

Static feedforward control structure of feedforward control is the most simple one, as long as the control block diagram of the feedforward controller transfer function can meet the type:

$$
W_{m}(\mathrm{~s})=-K_{m}=-\frac{K_{f}}{K_{0}}
$$

where, $K_{f}$ and $K_{0}$ is for interference channels and control the static gain

Static feedforward control only has good compensation to the steady-state (static) response of disturbance (control) . Due to the static feedforward controller being for a proportional regulator, implement is very convenient, so when little change in the disturbance or for compensation (control) requirement is not high, the production of static feedforward control structure can be used.

\section{2dynamic feedforward control system}

As for production process where Disturbance changes frequently and dynamic accuracy requirement for higher, the dynamic feed-forward scheme should be adopted. After using dynamic feed-forward, because it almost every time to compensate the disturbance affects the quantity of charged, it can greatly improve the dynamic performance of the control process, but the dynamic feed-forward controller structure is more complex, often need special control device, and even use a computer to achieve.and the system operation, parameter setting is more complex. Therefore, only when the technology of high control is accurat, other control scheme is difficult to meet, to consider using dynamic feed-forward scheme.

\section{Water spray cooling model for feed-forward compensation}

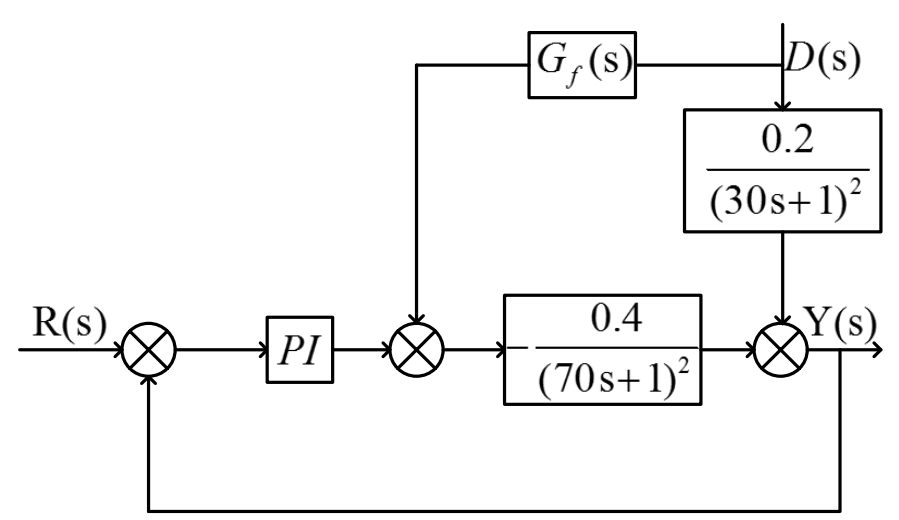

Figure 2 Water spray super-heating system block diagram

By selection above we can see the PI controller. this paper presents a specific example of a water spray desuperheating model, because the system does not have a high requirements of control technology, we can only take static compensation.

\subsection{Using the controller without feed-forward compensation}

Give the controller control, without adding feed-forward compensation link, the system simulats, observing the stable process of the system and the system stability after joining the rebalancing of disturbed system. 


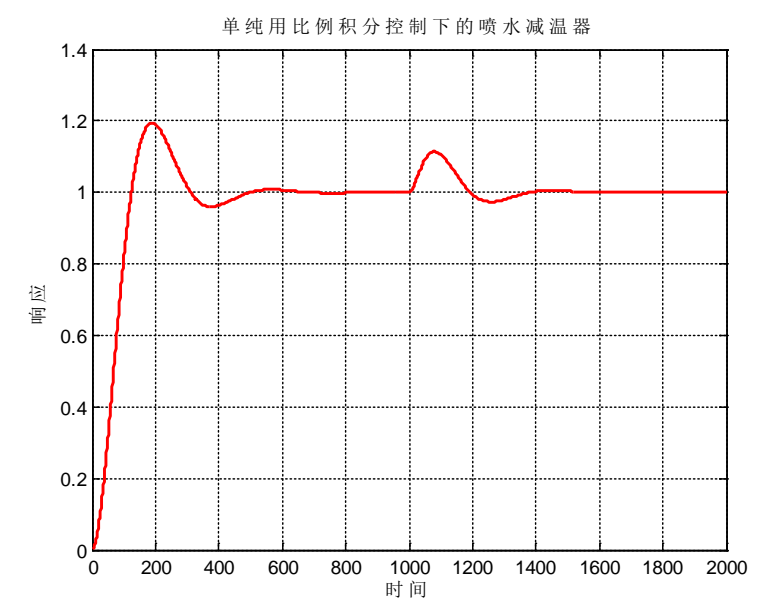

Figure 3 Only proportional integral control of water spray desuperheating system response curve

Under the action of outside interference ,the system on its own achieve to adjust the final originally stable curve to adjust back to steady, just with fluctuations being more obvious

\subsection{Use the PI controller control, static feed-forward compensation}

We add feed-forward compensation in order to eliminate the disturbance input on the system output which is the purpose of the impact of strong, if:

$$
D(s) \times G_{d}(s)+D(s) \times G_{f}(s) \times G(s)=0
$$

So we can get :

$$
G_{f}(s)=-\frac{G_{d}(s)}{G(s)}=-\frac{0.2}{(1+30 s)^{2}} \times \frac{(1+70 s)^{2}}{-0.4}=\frac{(1+70 s)^{2}}{2 \times(1+30 s)^{2}}
$$

make $s=0$, gained $G_{f}(s)$ is The transfer function of static feedforward compensation link is $G_{f}(s)=\frac{1}{2}$ in this example

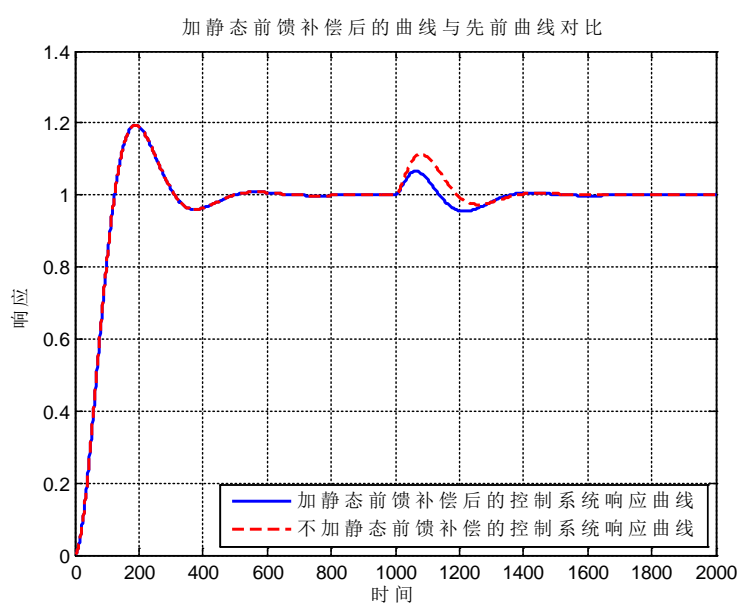

Figure4Response curves before and after static compensation

After joining static feedforward compensation, anti-interference ability of the system have been improved, in the presence of interference, changes in the system overshoot are caused by overshoot volume decreases, and system recovery with stable time also slightly decreases, and it shows that the static feedforward compensation for elimination of interference has a great effect.

\subsection{Static feedforward compensation model mismatch}

Alleged model mismatch, it is in a certain system calculate the feedforward linked to control a system, in this way, control effect will be obvious variation of the system. 


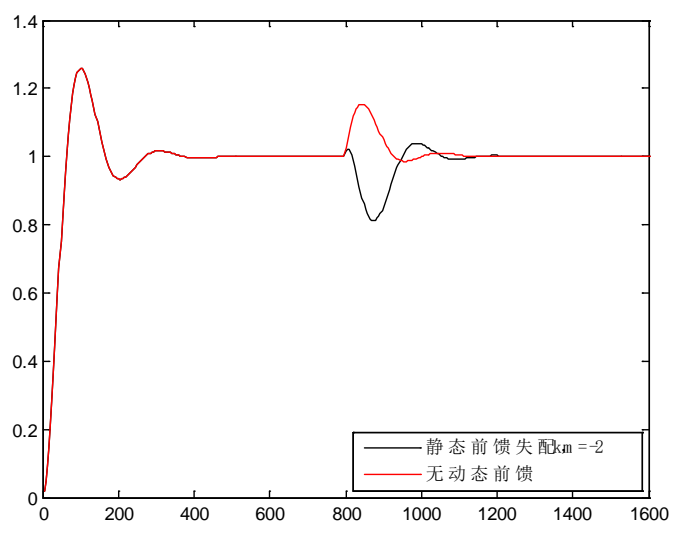

Figure5 Static model adaptation

Rapid downward fluctuation under the outer disturbance response curve for static model mismatch, it shows that feed-forward compensation should be established on the basis of sufficient understanding of the object, otherwise there will seriously affect the quality control model mismatch.

\section{Conclusion}

Through the this article, to static feed-forward compensation effect are analyzed in order to reduce temperature model, and put forward the model mismatch problem, practical engineering on the hysteresis and technical requirements of average accuracy can be used for reference in system control.

\section{Reference}

[1] Yang Zhousheng. Environment and Human health [M].Anhui Normal University Press, 2011.

[2] Deng Xue, Li Jiaming, Zeng Haojian. Research on Calculation Methods of AHP Weight Vector and Its Application [J]. Mathematics in practice and theory, 2012, 07:93-100.

[3]J. van der Geer, J.A.J. Hanraads, R.A. Lupton, The art of writing a scientific article, J. Sci. Commun. 163 (2000) 51-59. Reference to a book:

[4]W. Strunk Jr., E.B. White, The Elements of Style, third ed., Macmillan, New York, 1979. Reference to a chapter in an edited book:

[5]G.R. Mettam, L.B. Adams, How to prepare an electronic version of your article, in: B.S. Jones, R.Z. Smith (Eds.), Introduction to the Electronic Age, E-Publishing Inc., New York, 1999, pp. 281-304.

[6]R.J. Ong, J.T. Dawley and P.G. Clem: submitted to Journal of Materials Research (2003)

[7]P.G. Clem, M. Rodriguez, J.A. Voigt and C.S. Ashley, U.S. Patent 6,231,666. (2001)

[8] Information on http://www.weld.labs.gov.cn 